Journal of Universal Language 7

September 2006, 65-120

\title{
Questions in Natural and Artificial Languages
}

\author{
Christo Moskovsky \& Alan Libert
}

University of Newcastle

\begin{abstract}
All natural languages have interrogative constructions. This paper is a survey of the structure of the two major kinds of questions, yes-no questions and wh-questions in natural languages and artificial languages. There are several ways used to form each of these types, and sometimes more than one method is used in the same question. Yes-no questions can involve particles, a different word order than statements (namely different order of the subject with respect to a verb, the result of subject-verb inversion), and/or a different intonation pattern, while wh-questions will contain a wh-phrase, which may undergo movement, and subject-verb inversion may also take place. Natural languages are presented first, along with two relevant language universals. Artificial languages are then presented, and it will be seen that on the whole they are not significantly different from natural languages in how they form questions. Finally some recommendations for language designers are discussed.
\end{abstract}

Keywords: interrogative, question, syntax, artificial language 


\section{Introduction}

Language universals reflect features/patterns of language which are very widely spread across natural languages. ${ }^{1}$ They can be divided into two basic categories: absolute universals of the type "feature $\mathrm{X}$ is present in all known human languages", and implicational universals of the type "the presence of feature $X$ in a language implies the presence of feature $\mathrm{Y}$ in that language". Both categories are undeniably interesting and deserve the artificial language (AL) constructor's attention as they most probably represent some essential properties of language and as such should be considered for inclusion in the grammatical systems of artificial languages. In a series of papers (see Libert \& Moskovsky 2002, 2003; Moskovsky \& Libert 2004) we have reviewed some grammatical categories, viz., reflexivity, passive voice, and relative clauses, which are so widely represented in natural languages that can safely be described as absolute universals. Another such widely spread category is interrogative constructions: a survey of typological literature confirms that all known human languages use question-like constructions which are formally distinct from

1 We use the following abbreviations in glosses of examples:

$\begin{array}{lll}\text { AUX-auxiliary verb } & \text { IO-indirect object } & \text { PST-past } \\ \text { CTF-contrary to fact } & \text { NQ-negative question particle } & \text { PSTPTCP-past participle } \\ \text { DAT-dative } & \text { PASS-passive } & \text { Q-question particle } \\ \text { DO-direct object } & \text { PERF-perfect } & \text { REFL-reflexive } \\ \text { FUT-future } & \text { P-person } & \text { SG-singular } \\ \text { GEN-genitive } & \text { PL-plural } & \text { TOP-topic } \\ \text { IMPF-imperfect } & \text { PRES-present } & \\ \text { INSTR-instrumental } & \text { PRESPTCP-present participle } & \end{array}$

Also, "OT" indicates that a translation is by us, rather than being made by the source, while "tr." means translation in the source. We have sometimes not indicated the internal structure of words where this was not relevant. Sometimes we have left out a translation when the word for word gloss was sufficient for understanding the meaning of the example. 
corresponding non-questions (see, e.g., Bolinger 1968 among many others). In what follows, we review some of the most common properties of interrogative constructions in natural languages and then see to what extent these are represented in existing ALs. Based on this, we also offer prospective language constructors some recommendations in relation to the optimal design of interrogative constructions in a new AL.

\section{Natural Languages}

Typological studies dealing with interrogative constructions have identified a variety of question types, but only two among them seem to be universally represented in natural languages: Yes-No or NEXUS questions (YNQs) and $W h$-questions (WHQs). Furthermore, the YNQ-WHQ dichotomy seems to be found in all known human languages. This paper will focus on the properties of these two question types and will not deal with other interrogative constructions, such as echo questions, alternative questions, and rhetorical questions. ${ }^{2}$

In relation to YNQs and WHQs, it should be noted that universally they are derived, and formally marked as distinct, from corresponding declarative clauses:

(1) $\{\ldots$ STATEMENT $\ldots\}\}_{\text {declarative }}$

$$
\left.\rightarrow\left\{\ldots \text { STATEMENT } \ldots \mathbf{M}_{\mathbf{q}} \ldots\right)\right\}_{\text {NTERrogative }}
$$

(1) illustrates the most typical case of derivation of a question: the question involves the original statement and a formal interrogative

2 As a matter of fact, in most cases these more 'special' interrogative constructions bear most or all of the features of the two basic types, YNQs and WHQs. We also will not be discussing indirect questions. 
marker $\left(\mathrm{M}_{\mathrm{q}}\right)$. The actual form of this marker or its relative position inside the statement is subject to crosslinguistic variation, but there are nevertheless wide-spread commonalities across languages in the formal devices employed to mark questions: among them we most typically find intonation, change of word order and use of a question word or question particle (QP). ${ }^{3}$ We shall review each of these individually, but it should be noted that in many languages question formation involves a combination of two (as in the English example (2)) or even all three of these (as in the Yiddish example (3)):

(2) a. Will you come early? (intonation and Su-Aux inversion)

b. When will you come? (wh-word and Su-Aux inversion)

(3) a. Mojše hot gekoift a hunt.

Moses has bought a dog

'Moses bought a dog.'

b. Ci hot Mojše gekoift a hunt? (question particle and intonation and Su-Aux inversion)

Q has Moses bought a dog 'Did Moses buy a dog?'

(Sadock \& Zwicky 1985: 181)

In summary of this point, interrogative constructions are typically more marked than statements. The only exception that we are aware of is Greenlandic in which declarative sentences seem to have a special marker which is dropped in questions:

3 In some rare cases an affix can be used as a question marker, and it is almost always attached to the verb (Ultan 1978: 226). 
(4) a. Igavoq. cook-INDIC.3PSG

'He cooks.'

b. Igava? ${ }^{4}$

cook-3PSG

'Does he cook?'

(Sadock \& Zwicky 1985: 167)

In what follows, we will consider the three question markers most widely used in natural languages: intonation, inversion, and a designated question word and/or particle. In relation to the latter two (inversion and question word) we will briefly review an implicational universal determining the pattern of their occurrence in different languages. We will also address two question-related issues which have provoked a substantial amount of interest among linguists: the possibility of hosting multiple $w h$-words in sentenceinitial position, and locality constraints on $w h$-movement. ${ }^{5}$

\subsection{Intonation}

Intonation appears to be a very widely spread device for marking YNQs: in the vast majority of natural languages we find a distinct (usually final rising) intonation pattern in YNQs which is different from the intonation in corresponding declarative sentences, as in the Yiddish example (5), repeated here for convenience:

(5) a. Mojše hot gekoift a hunt. $\searrow$ Moses has bought a dog 'Moses bought a dog.'

4 There may also be a change in the intonation pattern, but our source is uninformative in relation to this.

5 The term ' $w h$-fronting' is also widely used in literature to describe sentenceinitial $w h$-words. 


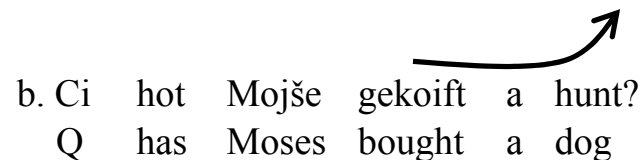

'Did Moses buy a dog?'

It seems that languages which do not involve a special intonation pattern in YNQs are quite rare: Greenlandic is reported as being one such language (Sadock \& Zwicky 1985: 181). It also seems that intonation is very rarely the only formal marker of interrogative constructions of the YNQ type: Jacaltec (Western Guatemala) appears to be an example of this (ibid.). In the vast majority of natural languages, the formation of YNQs involves both a special intonation pattern and another formal device: most commonly either subject-verb inversion (as in the English example (2)) or a question particle (or, less commonly, both - as with the Yiddish example above). In some rare cases, the two devices are in complementary distribution: e.g., in Chrau (Austro-Asiatic, Vietnam), or Easter Island (ibid.).

Rising final intonation is the most common, but certainly not the only possible intonational pattern used in interrogative constructions. In some languages with a 'floating' QP (such as Bulgarian; for more details, see next section), the (rising) interrogative intonation pattern is applied to the sentence constituent to which the QP is linked, with the QP effectively marking the boundary of the intonation pattern:

(6) a. Starijat chovek li chakashe na opashka za hljab? old.the man Q wait.PST on queue for bread 'Was it the old man that was waiting for bread in a queue?' $\begin{array}{lllll}\text { b. Starijat } & \text { chovek } & \text { na opashka li chakashe za hljab? } \\ \text { old.the man } & \text { on queue } & \text { Q wait.PST for bread }\end{array}$ 'Was it in a queue that the old man that was waiting for bread?' 
Sadock \& Zwicky (1985: 181) report that Hopi YNQs involve a special stress on the first word of the question.

It is noteworthy that interrogative intonation patterns apply almost exclusively to YNQs, but not WHQs. ${ }^{6}$

\subsection{Question Particle}

The question particle (QP) is also among the most common formal devices used as markers of interrogative constructions in natural languages. In a large number of languages QPs have a fixed position in the question: sentence-initial QPs (as in (3b) above) occur almost as frequently as sentence-final QPs (Ultan 1978: 226) ${ }^{7}$ :

(7) Sinhalese (Sri Lanka)

Jōn ballavə däkka də?

John dog saw Q

'Did John see the dog?'

(Lehmann 1978: 17)

We are aware of at least one language (Yaruba, Nigeria) in which YNQs are marked either with a sentence-initial QP or with a different sentence-final QP, never with both (Sadock \& Zwicky 1985: 181). In some languages, like Easter Island, the QP seems to be optional:

(8) Easter Island
a. He tokorua moni? ${ }^{8}$
(only marked with intonation)
exist your money
'Do you have money?'
(Chapin 1978: 148)

\footnotetext{
${ }^{6}$ According to Sadock \& Zwicky (1985: 181), in Diola (Western Africa) rising intonation is found in both YNQs and WHQs.

${ }^{7}$ Enclitic QPs following the linearly first word of the sentence are also treated as sentence-initial.

8 'He' seems to be an existential construction of the 'there is' type.
} 
b. Hoki he moni marite tokorua?

Q exist. money American your

'Do you have money?'

(ibid.: 155)

In languages with a fixed QP position, the QP position is often implicationally related to the basic word order of that language: sentence-initial QPs are almost always found in VO languages; with sentence-final QPs there is no such correlation, but such languages are often postpositional (Ultan 1978: 226). In about half of the languages involving a $\mathrm{QP}$, it is used exclusively to mark YNQs, while in the other half it may be used both in YNQs and WHQs (ibid.: 228).

(9) Japanese

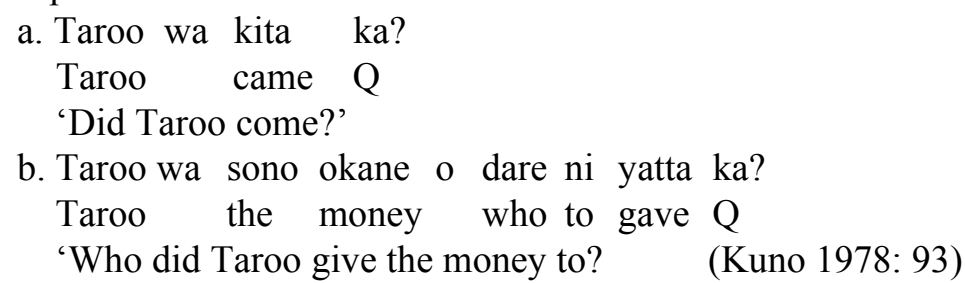

While fixed-position QPs seem to be the dominant type crosslinguistically, there are also languages in which the QP is attached (often as a proclitic or enclitic) to a particular sentence component; this may also involve a topicalisation-like change in the order of sentence constituents.

(10) Latin
a. Est-ne
puer bonus?
is-Q
boy good
'Is the boy good?'

9 'Hoki' is a word like 'whether', a subordinating marker for indirect questions, and an optional QP in direct YNQs. 


b. Puer-ne bonus est?
boy-Q good is
'Is it the boy who is good?'
c. Bonus-ne puer est?
good-Q boy is

'Is it good that the boy is?' (Sadock \& Zwicky 1985: 182)

Another such language is Bulgarian, in which QP can be attached to almost any component of the sentence (as noted in the previous section, the interrogative intonation pattern seems to "follow" the particle):

(11) a. Starijat chovek chakashe na opashka za hljab. old-the man wait-PST on queue for bread 'The old man was waiting for bread in a queue.'

b. Starijat li chovek chakashe na opashka za hljab? old-the Q man wait-PST on queue for bread 'Was it the old (rather than young) man that was waiting for bread in a queue?'

c. Starijat chovek li chakashe na opashka za hljab? old-the man Q wait-PST on queue for bread 'Was it the old man that was waiting for bread in a queue?'

d. Starijat chovek chakashe li na opashka za hljab? old-the man wait-PST Q on queue for bread 'Was the old man waiting in a queue for bread?'

e. Starijat chovek na opashka li chakashe za hljab? old-the man on queue $Q$ wait-PST for bread 'Was it in a queue that the old man that was waiting for bread?'

f. Starijat chovek za hljab li chakashe na opashka? old-the man for bread Q wait-PST on queue 'Was it for bread that the old man that was waiting in a queue?' 
There are some limitations on where the QP can occur in a Bulgarian YNQ: e.g., it is impossible to position it in between a preposition and a noun:

(12) *Starijat chovek za li hljab chakashe na opashka? old-the man for Q bread wait-PST on queue 'Was it for bread that the old man that was waiting in a queue?'

Sentence-initial and sentence-final QPs necessarily have scope over the whole proposition, while 'floating' QPs typically only have scope over the constituent they are attached to. Note, however, that when QP is positioned following the verb, it can refer to the verb itself or the whole proposition.

\subsection{Inversion}

Inversion most commonly involves inverting the sentence subject and the finite form of the verb. In English, it is generally an auxiliary verb, but in other languages, such as German, it can also be the main verb:

(13) Besuchen Sie die Vorlesungen? attend you the lecures 'Do you attend the lectures?'

Inversion and QPs do not usually co-occur as question markers in YNQs: in most of the cases we are aware of YNQs marked with a QP do not involve inversion: 
(14) Thai (a typical SVO language)

Khăw kin khâaw măy?

he eat rice $Q$

'Does he eat rice?'

(Lehmann 1973: 60-1, cited in Mallinson \& Blake 1981)

(15) Sinhalese (an OV language)

Jōn ballavə däkka də?

John dog saw Q

'Did John see the dog?'

(Lehmann 1978: 17)

(16) Irish (a typical VSO language)

An bhfaca Seán an madadh?

Q saw Sean the dog

'Did John see the dog?'

(17) Mandarin

Nii bu pah laohuu ma? ${ }^{10}$

'Aren't you afraid of tigers?'

(Ultan 1978: 216)

The only language in our sample that does involve both inversion and a QP in the formation of YNQs is Yiddish:

(18) $\mathrm{Ci}$ hot Mojše gekoift a hunt?

Q has Moses bought a dog

'Did Moses buy a dog?' $\quad$ (Sadock \& Zwicky 1985: 181)

In WHQs occurrence of inversion, alongside a wh-word, is not uncommon; this is the case with German as well as most of the major Western languages:

${ }^{10}$ This source has not provided glosses for the non-English examples, but the author has made it clear that 'ma' is a QP. 
(19) Wann haben Sie Ihr Studium beendet? when have you your studies finished 'When did you finish your (university) studies?'

Overall, word-order changes as formal markers of interrogative constructions, such as inversion, seem to be quite common in the major Western languages, but rare elsewhere.

\section{4. $W h$-Words}

There is wide agreement in typological literature that whquestions (WHQs), in other words, questions involving a $w h$-word, are found in all natural languages ${ }^{11}$ (Ultan 1978: 228). Most typically there are $w h$-words such as 'who' and 'what' which are nominal in nature and usually target noun phrase arguments of the verb. Adverbial wh-words like 'where', 'when', 'how', etc. performing a wide range of adverbial functions (locative, temporal, manner, purpose, etc.) are also found in most, if not all, human languages. Some languages involve a wh-numeral (e.g., Latin quot 'how many?'). Much less frequent is the use of verbal wh-words, or wh-verbs: Sadock \& Zwicky (1985: 184) report that $w h$-verbs are found in Southern Paiute (an Uto-Aztecan language), e.g., aran-i means 'to do what?', 'to act how?', 'to have what happened to one?'. In some rare cases, $w h$-words are formed by attaching a suffix to the nominal targeted by the question:

(20) Rotuman (Austronesian)

Hanue-s? ${ }^{12}$

'Which country?'

(Ultan 1978: 229)

\footnotetext{
${ }^{11}$ The only exception we are aware of is Hopi in which there are no $w h$-words, and questions resemble indefinite statements like Someone came?

12 ' $-\mathrm{s}$ ' is a Q-suffix, attached to the noun.
} 
The $w h$-word can sometimes also be part of a $w h$-NP (e.g., an attributive modifier of the head noun):

(21) Russian

$\begin{array}{lll}\text { Kakim } & \text { nozhom on kushaet? } \\ \text { which-INSTR knife } & \text { he dines }\end{array}$

'Which knife is he dining with?'

In languages with a morphological case system $w h$-words would be marked for case:

(22) Russian

Komu ty dal svoju ljagushku? who-DAT you gave your frog

'Who did you give your frog?'

(23) German

Mit welchem Problem beschäftigen Sie sich jetzt? with which-DAT problem deal you self now

'What problem are you dealing with at the moment?'

As the German example above illustrates, a $w h$-word can occur as part of a prepositional phrase (or even a larger structural unit). Typically, prepositions occur in front of the $w h$-word: languages like English (and the Scandinavian languages) in which the preposition associated with the $w h$-word can occur elsewhere in the sentence (often in sentence-final position ${ }^{13}$ ) seem to be relatively rare:

(24) What are you looking at?

As already stated earlier in the paper, crosslinguistically, WHQs

${ }^{13}$ A situation commonly described in literature as "preposition stranding". 
are rarely marked with a special interrogative intonation, but in approximately half of the cases, a QP is also used (see Japanese example 9b). Subject-verb inversion is also common in WHQs, especially among the European languages (see for instance the German example (23)). Another widely spread commonality in WHQs across languages is the distinction between human and nonhuman wh-words (e.g., 'who', 'what'); some languages (also) make a distinction between animate and inanimate $w h$-words (Ultan 1978: 229).

Wh-words in most languages (probably up to three-quarters of the known human languages) occur in sentence-initial position: English, German, Russian are all such languages; an example of a nonEuropean language with question-initial $w h$-words is Easter Island:

$$
\begin{aligned}
& \text { (25) Aai i } \quad \text { toke? } \\
& \text { who PERF } \\
& \text { 'Who stole (it)?' }
\end{aligned}
$$

Languages in which $w h$-words have a fixed position somewhere else in the sentence are quite rare: Khasi (Austro-Asiatic) is reported as having its $w h$-words in sentence-final position, while in Gujarati the $w h$-word is always positioned in front of the verb phrase (Ultan 1978: 229). In about a quarter of the world's languages the $w h$-word occurs in the position of the sentence constituent which is targeted by the question; Japanese is one such language:
(26) Taroo wa sono okane o dare ni yatta ka? Taroo the money who to gave $Q$ 'Who did Taroo give the money to?

(Kuno 1978: 93)

In some languages (e.g., Malay) the wh-word can occur either sentence-initially or in the position of the sentence constituent which is targeted by the question: 
(27) a. Siapa (yang) Bill harap yang akan membeli

Who (that) Bill hope that will buy

baju untuk-nya?

clothes for-him

'Who does Bill hope will buy clothes for him?'

b. Ali memberitahu kamu tadi Fatimah

Ali informed you just-now Fatimah

baca apa?

read what

'What did Ali tell you Fatimah was reading?'

(Cole \& Hermon 1998: 224)

\subsection{Wh-Movement}

Issues of the relative position of the $w h$-word in the sentence are often analysed in terms of syntactic movement (or non-movement) of the wh-word from a sentence-internal to sentence-initial position. ${ }^{14}$ In this approach the German example in (22) would be treated as having been derived from an underlying abstract level of representation (e.g., D-structure) with the following composition:

(28) Sie beschäftigen sich [mit welchem Problem] jetzt?

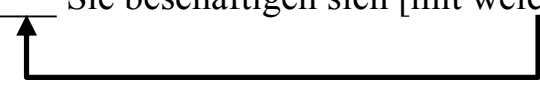

The wh-movement analysis has been very influential for a number of reasons, but most of all because it offers a systematic explanation of the distribution of $w h$-words in the world's languages: in some languages (like English) wh-movement is required and the wh-word must be placed in sentence-initial position ${ }^{15}$; in other languages (like

${ }^{14}$ The term "wh-fronting" is also commonly used to refer to the same phenomenon.

${ }^{15}$ According to a universal discussed in Hawkins (1999), if a language involves $w h$-movement, it is always to the left periphery of the sentence, never to the right. 
Japanese) $w h$-movement is not involved and the $w h$-word remains in situ; there are also languages (like Malay) in which wh-movement is optional, and the $w h$-word can either move to sentence-initial position, or stay in its sentence-internal position. ${ }^{16}$ It should be noted that in languages in which $w h$-words normally have a fixed sentence-initial position, echo-questions and questions with multiple $w h$-words (in which some of the $w h$-words do occur in sentenceinternal positions) provide some empirical support for the movement hypothesis:

(29) You are going to do what? (echo)

(30) Who is going to do what?

The wh-movement analysis has also manifested a serious potential to provide an account for a number of question-related phenomena, including the so called "islands". Empirical evidence from a wide range of typologically distinct languages with fixed sentence-initial $w h$-words indicates that, universally, not all grammatical statements yield a grammatical WHQ with a sentenceinitial $w h$-word. In other words, there seem to be restrictions on the types of positions (also called "extraction sites") out of which whmovement is allowed. Consider the following two English examples:

(31) a. John believes [s that Bill deceives his wife]. $\rightarrow$

b. Who does John believe [s that Bill deceives ] ?

\footnotetext{
${ }^{16}$ In generative theory, it is now widely assumed that even in languages like Japanese, in which the $w h$-word is positioned sentence-internally, some covert form of $w h$-movement takes place (at some more abstract level of representation, called Logical Form, or LF); it is unclear how much such a hypothesis is supported with language-specific empirical evidence.
} 
(32) a. John believes [NP the rumour [s that Bill deceives his wife]]. $\rightarrow$ b. ${ }^{*}$ Who does John believe the rumour [s that Bill deceives ?

As these examples illustrate, while (31a) yields the completely grammatical question (31b) targeting the underlined NP, the same is not true of (32a): deriving a corresponding WHQ in this case is not allowed. An informal generalization of such constraints on whmovement (see, e.g., Napoli 1993: 404) seems to be that whextraction is not allowed from complex NPs (also commonly involving a relative clause modifier), from within sentential subjects, and from adverbial clauses:

(33) a. [subject NP Rumours about [NP the party]] upset Bill. $\rightarrow$ b. *What do [rumours about ___ upset Bill?

(34) a. Bill left [adverbial s before his wife arrived at [NP the party]]. $\rightarrow$ b. *What did Bill leave [before his wife arrived at __ ]?

Following Ross (1970), structures which do not allow whextraction have informally been called "islands". A more formal analysis in terms of syntactic barriers (to movement) is provided by Chomsky (1986): according to Chomsky's analysis, some structural constituents can block (wh-)movement, and it is posited that movement over two such constituents is disallowed; in English these 'blocking' constituents are NP and S (but may be different in other languages). Ultimately, the barriers approach proposed the Subjacency Principle as one of the universal properties of natural language. Indeed, evidence from typologically distant languages seems to provide support for the existence of a universal constraint on wh-movement: 
(35) Malay

*Di mana $_{i}$ [kamu fakir [Ali suka [perempuan yang

at where you think Ali like woman who

tinggal $\left.\left.\left.\mathrm{t}_{i}\right]\right]\right]^{17}$

live

'You think Ali likes the woman who lives where?'

(Cole \& Hermon 1998: 227)

Cole and Hermon provide a list of such Malay sentences showing that $w h$-movement in this language is subject to the full range of island constraints that we find in languages like English.

\subsection{An Implicational Universal}

Typological studies (most commonly associated with the name of Joseph Greenberg, see Greenberg 1963) have identified an implicational universal which links subject-verb inversion with the relative position of the $w h$-word in the sentence. This universal can formally be expressed as follows:

\section{(36) WHQ inversion $\rightarrow W h$-fronting}

In informal terms, (36) posits that subject-verb inversion in WHQs implies movement of the wh-word to sentence-initial position. In other words, if a language involves inversion as a formal marker of WHQs, then the wh-word must undergo syntactic movement to the front of the sentence. This is indeed the case in English and German (and most of the European languages). The reverse condition (viz., that no inversion implies no movement) is not valid: there are languages which involve no inversion and in

17 The ' $\mathrm{t}$ ' here is a notation marking the presumed original position of the wh-word 'mana'. 
which the wh-word remains in situ as, e.g., in the Japanese example repeated here for convenience:

(37) Taroo wa sono okane o dare ni yatta ka?

Taroo the money who to gave $\mathrm{Q}$

'Who did Taroo give the money to?

(Kuno 1978: 93)

There are also languages in which $w h$-words do occur in sentence-initial position without subject-verb inversion, such as Finnish. Languages which involve WHQ inversion, but no whmovement are not known to exist. The working of this typological universal is illustrated in the following table:

(38)

\begin{tabular}{|c|c|c|l|l|}
\hline $\begin{array}{c}\text { LANGUAGE } \\
\text { TYPE }\end{array}$ & $\begin{array}{c}\text { SUBJECT-VERB } \\
\text { INVERSION IN } \\
\text { WHQS }\end{array}$ & WH-MOVEMENT & \multicolumn{1}{|c|}{ EXAMPLE } & LANGUAGES \\
\hline \hline A & + & + & Whom can John see? & English \\
\hline B & - & - & John can see whom? & Japanese \\
\hline C & - & + & Whom John can see? & Finnish \\
\hline D & + & - & Can John see whom? & none \\
\hline
\end{tabular}

after Eckman et al. (1989: 177)

There is an extension to this universal which relates subject-verb inversion in WHQs to subject-verb inversion in YNQs: this can formally be expressed as follows:

(39) YNQ inversion $\rightarrow$ WHQ inversion

(39) posits that languages which involve subject-verb inversion in YNQs must also involve subject-verb inversion in WHQs. The working of this typological universal is illustrated in the following table: 


\begin{tabular}{|c|c|c|c|c|}
\hline $\begin{array}{c}\text { LANGUAGE } \\
\text { TYPE }\end{array}$ & $\begin{array}{c}\text { SUBJECT-VERB } \\
\text { INVERSION IN } \\
\text { YNQS }\end{array}$ & $\begin{array}{c}\text { SUBJECT-VERB } \\
\text { INVERSION IN } \\
\text { WHQS }\end{array}$ & EXAMPLE & LANGUAGES \\
\hline \hline A & + & + & $\begin{array}{c}\text { Can John see Mary? } \\
\text { Whom can John see? }\end{array}$ & English \\
\hline B & - & - & $\begin{array}{c}\text { John can see Mary? } \\
\text { John can see whom? }\end{array}$ & Japanese \\
\hline $\mathrm{C}$ & - & + & $\begin{array}{c}\text { John can see Mary } \\
\text { Whom can John see? }\end{array}$ & Lithuanian \\
\hline *D & + & - & $\begin{array}{c}\text { Can John see Mary? } \\
\text { Who John can see? }\end{array}$ & None \\
\hline
\end{tabular}

after Eckman et al. (1989: 177)

We can combine (36) and (39) to derive the following universal:

(41) YNQ inversion $\rightarrow$ WHQ inversion $\rightarrow$ Wh-movement

(41) seems to be a very wide-spread, possibly absolute, ${ }^{18}$ universal.

\subsection{Wh-Movement of Multiple $W h$-Words}

In the final section of the first part of this paper, we will briefly consider an issue, viz., the possibility to place more than one whword in sentence-initial position, which seems to have received a substantial amount of attention in literature, and which may be relevant to the design of interrogative constructions in ALs.

It appears that natural languages differ in relation to how many $w h$-words are allowed in sentence-initial position. Languages like English only allow a single wh-word to move to the front of the sentence:

\footnotetext{
${ }^{18}$ It should be noted that Ultan (1978) has identified Khasi as an exception to this universal, although this claim has been disputed.
} 
(42) a. Bill expects his wife to cook the dinner. $\rightarrow$

b. Who does Bill expect to cook the dinner?

c. What does Bill expect his wife to cook

d. Who does Bill expect to cook what?

e. *Who what does Bill expect to cook

As this example illustrates, in English it is completely all acceptable to have more than one $w h$-word in the WHQ, but only one of them is allowed to occur in sentence-initial position. In contrast, some languages allow multiple $w h$-words at the beginning of the sentence:

(43) Bulgarian
a. John e kazal na Mary da dojde. $\rightarrow$ John is told to Mary to come 'John (has) told Mary to come.'
b. Koj e kazal na Mary da dojde? who is told to Mary to come 'Who (has) told Mary to come.'?
c. $\mathrm{Na}$ kogo e kazal John __ da dojde? To whom is told John to come 'Whom did John tell to come?'
d. Kakvo e kazal John na Mary what is told John to Mary
'What did John tell Mary?'
e. Koj kakvo na kogo __ e kazal who what to whom is told 'Who said what to whom?'

In the Czech language, the picture seems to be very much the same: 

(44) Kto co komu dal?
who what to-whom gave
'Who gave what to whom?'

There are, of course, also languages like Japanese which disallow $w h$-words in sentence-initial position altogether.

This completes our necessarily brief discussion of interrogative constructions in natural languages. Next we shall see how this grammatical category is represented in a range of artificial languages.

\section{Artificial Languages}

We have only examined a fraction of the more than a thousand ALs that have been created and cannot claim to be presenting a systematic survey, but by looking at a fair number of ALs we might get an idea of what tendencies they have with respect to question formation. Obviously what happens in ALs will probably be largely a result of which natural language(s) (if any) they are based on.

\subsection{Yes-No Questions}

As we know, there are three main ways in which YNQs are formed: by adding a particle, by changing word order, and by changing intonation. Some ALs may use only one of these methods, and some may use more than one.

\subsubsection{Particles}

Some ALs mark YNQs with a particle. This is true of Arulo, which inserts $k a$ or $k a d$ (apparently depending on whether the next 
word begins with a consonant or a vowel): ${ }^{19}$

(45) Kad el esas felica?

Q she is happy

'Is she happy?'

(Talmey 1925: 17)

YNQs in Eurolang are introduced by quiz, with no change in word order from the corresponding statement:

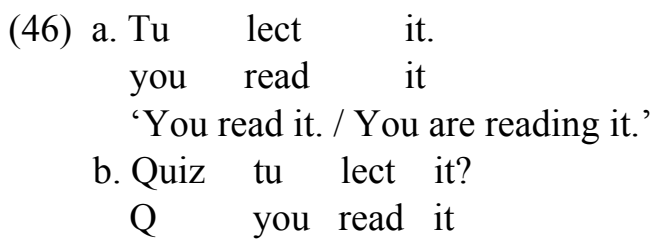

'Do you read it? / Are you reading it?' (Hunt 1998: section 6)

YNQs in SASXSEK are derived from statements through placing $h a$ in the first position in the sentence. Notice the lack of inversion in the example below (and that there is no question mark); all types of sentences finish with a period.

${ }^{19}$ There is a possible counter-example in Talmey (1925: 20), i.e., a YNQ with no particle:

(i) "A tua enemikino," on klamis al li, "tu konditas to your female.enemy one shouted[?] to him you conduct so ecelante?"

so excellently

"“You behave so well towards your enemy?" one shouted.'

(Talmey 1925: 20)

One could perhaps argue that this is not a significant violation of a rule requiring YNQs to begin with a particle on the grounds that it is really an exclamation and not a question and/or because it is a quotation, and an interrupted one at that. 
(47) a. Lo ven fu kitabuk. he go to library 'He is going to the library.'
b. Ha lo
ven fu
kitabuk
Q he go to library
'Is he going to the library?'

(Nutter 2006: 10)

Esperanto also has a sentence initial particle for marking YNQs, $\underline{\hat{c} u}$ :
(48) $\hat{\mathrm{Cu}}$ li estas tie? Q he is there 'Is he there?'

(Butler 1965: 29)

Esperanto has free word order with respect to major sentence constituents, and this applies to questions as well as statements. Butler (ibid.: 30) says that "An unusual order may emphasize a particular word", and gives the following example:

(49) $\hat{\mathrm{Cu}}$ tie li estas?

Q there he is

'Is it there that he is?'

Thus there is no subject-verb/auxiliary inversion (as a particular rule) in Esperanto YNQs. It is possible to mark YNQs in Esperanto only with intonation, according to Butler (ibid.), "Sometimes, in conversation, $\hat{c} u$ is omitted, the question being implied by the tone of voice. Li estas tie? 'He is there?' But this is not usual." However, Wennergren (2005: section 22.2) gives a different idea about the formation of Esperanto questions without $\hat{c} u$ :

In dialogue $\hat{c} u$ can sometimes be left out. Only the context then shows that a question is involved. Those $\hat{c} u$-less $\hat{c} u$ questions are acceptable when the whole sentence is drastically 
shortened: $[\ldots]$

— Tomorrow I shall go to India! - to Delhi? = ... Will you go to Delhi?

Many speakers use a special manner of saying questions. They use e.g. a rising tune at the end of the sentence. But in Esperanto there do not exist rules concerning intonation. Therefore, if one uses a $\hat{c} u$-question without $\hat{c} u$, only the context can show that the sentence is a question. (OT)

Gilo has a sentence-initial question particle, $k$, and there is no rule requiring subject-verb inversion (nor do question marks seem to occur):

$$
\begin{aligned}
& \text { (50) K yu vez kãr? } \\
& \mathrm{Q} \text { you have car } \\
& \text { 'Do you have a car?' }
\end{aligned}
$$

(Ciles 2006: section 12.3)

However, inversion is "grammatically possible" (ibid.: section 12.5):

$$
\begin{aligned}
& \text { (51) } \mathrm{K} \text { ad-it-oz li? } \\
& \text { Q ?-eat-PST }{ }^{20} \text { they } \\
& \text { 'Did they eat?' }
\end{aligned}
$$

A part of a sentence to be questioned can be moved to the usual position of the subject, i.e., where it will be the first constituent after $k$ :

$$
\begin{array}{cccc}
\text { (52) a. K yu } & \text { f-ez } & \text { bir? } \\
\text { Q you } & \text { like-PRES } & \text { beer } \\
\text { 'Do you like beer? } & &
\end{array}
$$

\footnotetext{
${ }^{20} \mathrm{We}$ do not understand the function/meaning of the prefix $a d-$. There is a passive affix with this form, but this sentence does not appear to be passive. It seems to occur with one or more non-standard word orders, as can also be seen in the next example.
} 


$$
\begin{array}{llll}
\text { b. } \mathrm{K} \quad \text { ad-f-ex } & \text { yu } & \text { bir? } \\
\text { Q } & \text { ?-like-PRES } & \text { you } & \text { beer } \\
\text { 'Do you like beer?' } & &
\end{array}
$$

(ibid.: section 12.4)

This is not surprising given the generally free word order of the language. A particular word in the question can be stressed, which presumably would indicate that that word is being questioned.

In the Blue Language the particle $d u$ is used to form YNQs; it belongs to the part of speech of that language called "staffwords", which "includes expressions of general ideas and certain very useful abbreviations" (Bollack 1900: 7). Another staffword, tnu, appears in negative YNQs (created by combining $d u$ with the negative marker $n u$ 'not') ${ }^{22}$. According to Bollack (ibid.), "These staffwords despense with varying the tonality of the voice." Bollack (1899: 179) makes a stronger statement: "the interrogative tonic accent, indispensable in certain languages (in Italian for example), is completely suppressed in B [=the Blue Language]" Bollack (1900: 49 ) indicates that the Blue Language does not have freedom of word order: "every type of phrase will always have a single constructure [sic]. Though the necessity of expressing all propositions in a strict order be a painful constraint to the speaker's or to the writer's mind, this prescription is absolutely necessary in an international language." ${ }^{23} \mathrm{He}$ indicates (ibid.) that questions have the same order as statements. Bollack states (ibid.: 37) that "The PLACE of the

${ }^{21}$ Apparently this is both the normal word order for questions and an order which can be used when the subject is being questioned.

${ }^{22}$ However, if a negative question contains a reflexive pronoun (which is also a staffword), then $d u$ is used along with the negative reflexive pronoun: Bollack (ibid.: 37) states, "In case of interrogation in a pronominal verb, with idea of negation, the negation remains in the Staffword indicating the reflex. Ex.: 'Do I not love myself?' The translation is: Me du snu lovo? (I-do myself-not-love?) and not: Me tnu su lovo?"

${ }^{23}$ On the next page he says that there is some freedom "in the place of the member of phrase [sic] containing a gerundive participle". 
staffwords is always immediately before the word to which they relate." In the all of the YNQs of the Blue Language that we have seen, $d u$ and $t n u$ occur immediately after the subject, e.g.:

\begin{tabular}{|c|c|c|}
\hline (53) a. Me & $\mathrm{du}$ & lovi? \\
\hline I & Q & love \\
\hline 'Do & e?' & \\
\hline b. Me & tnu & lovi? \\
\hline I & NQ & love \\
\hline
\end{tabular}

'Do I not love?'

(ibid.: 12)

c. Per du lovo fant?

father Q love child

'Does the father love the child?'

d. $\mathrm{A} y$ per tnu lovo точ sea fant lalged?

this father NQ love much his child ill

'Does this father not love much his ill child?' (ibid.: 50)

Given the just quoted remark by Bollack, one might think that if one were questioning the subject, i.e., Do I love?, $d u$ or $t n u$ would precede it. However, this may not be the case: Bollack (1899: 188) says that Have I not loved? when it means 'Am I not loved, me!' "is regularly translated" as em tnu ulovo? (em "indicates the exclamative mood" (ibid.).) There can be more than one staffword between the subject and the verb; Bollack (ibid.:189) states, "for the most frequent uses" the interrogative staffword is "always ... the farthest from the verb". We can see this in the example below, which contains three staffwords, $d u$, su, and $r u$.

(54) $\mathrm{Me}$ du su ru lovo?

I Q REFL again love

'Do I love myself again?'

(Bollack: 1899)

aUI also indicates YNQs with a particle, $h I$, but it occurs at the 
end of the question ${ }^{24}$ :

(55) $\mathrm{Vu}$ dov nod, hr?

he eats bread $Q$

'Does he eat bread?' = 'He eats bread, eh?'

(Weilgart 1979: 49)

It seems that this particle can also occur in WHQs, since Weilgart (ibid.) states that it "may follow any question". However, we know of no examples of this, although there are WHQs which are immediately followed by $h_{I}$ (indicated by punctuation to be a separate sentence), e.g.:

(56) Yug hud, jag ynam to gaf rykøm oyt, but how while small seed or humble egg fu wac-yec tykwev a? hr? I can-CTF conquer space $\mathrm{Q}$ 'but how, as a tiny seed or humble egg, could I conquer space?'

(ibid.: 166, tr. 168)

There is at least one YNQ in Weilgart (ibid.) which does not contain $h r^{25}$

${ }^{24}$ The $h I$ would be seen as a tag question by at least some researchers. However, given that this is the only way that (something like) YNQs can be formed in aUI, one might rather consider $h_{I}$ to be part of of YNQs. One might also question the separation of tag questions as a separate type from YNQs.

${ }^{25}$ In Weilgart (1979), including twice in the same paragraph in which this example occurs, there are YNQs which do not themselves contain $h I$, but which are followed immediately by it, e.g.:

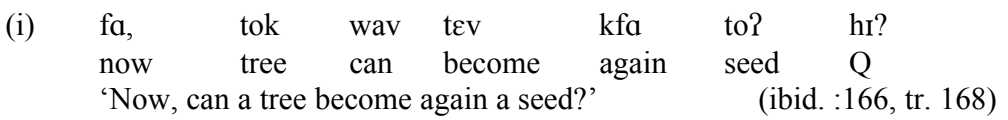


$\begin{array}{llllll}\text { (57) To cev } & \text { uj } & \text { nam } & \text { uj tok? } \\ \text { seed is as } & \text { big as } & \text { tree }\end{array}$

'Is the seed as big as the tree?' (ibid.: 166, tr. 168)

In Meiko as well, the formation of a YNQ involves something placed after a statement, not a dedicated interrogative particle, but the words o na 'or not', e.g., To kome, o na? 'You come, or not?/ Do you come?' (Garet no date).

Cárdenas (1923: 153) indicates that the Hom-Idyomo interrogative marker $\tilde{c} u$ is optional; if it is present the order is subjectverb, if it is not there is subject-verb inversion: ${ }^{26}$

${ }^{26}$ The following questions contain a different particle, an, and also have the order copula-complement-subject:

(i) a. Kay an estay justas las sentencos? and Q[?] are just the sentences

'And are the sentences just?' $\quad$ (Cárdenas 1923: 47)

b. An iray bi por negoyos?

$\mathrm{Q}$ [?] go you for

'Do you go there for business?' (ibid.: 97, tr. 99)

We do not understand the difference in meaning or function, if any, between $\tilde{c u}$ and an; the latter word is not in the Hom-Idyomo dictionary in Cárdenas (1923). Also on p. 1:97 there is an instance of an in a WHQ, following the $w h$-word, and on the following page it occurs in a request and in a relative clause, making it still more difficult to understand its function. The same word order occurs elsewhere, without a particle, e.g.:
(ii) Estay sinceras cia devoto kay cia patriotism?
is sincere that devoutness and that patriotism
'Is that devoutness and patiriotism sincere?' (ibid.: 40)

Perhaps the (unstated) rule is that with questions containing a copula if the subject is a pronoun (as in (ib)), it precedes the complement, otherwise the complement precedes it.

The following question has a word order not mentioned in any explicit rules:

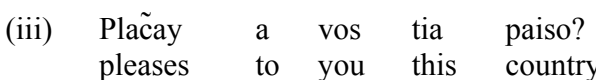

'Do you like this country?'

(ibid.: 74, tr. 75) 


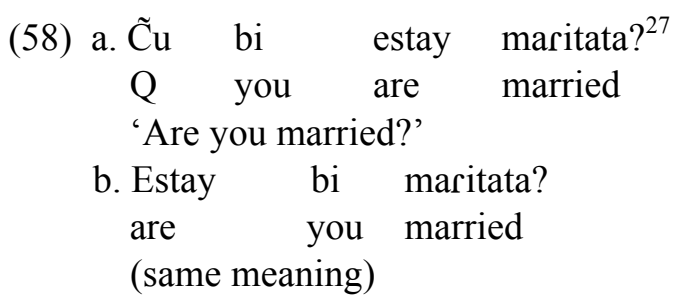

There are at least two YNQs in Cárdenas (1923) which involve neither a particle nor inversion, one of which is below:

$\begin{array}{lllcll}\text { (59) Una } & \text { gratifiko } & \text { da } & 20 & \text { frankos } & \text { pro } \\ \text { a } & \text { tip } & \text { of } & 20 & \text { francs } & \text { for } \\ \text { la } & \text { conducisto } & & \text { sufic-oy? } & \\ \text { the } & \text { chauffeur } & & \text { suffice-FUT } & \end{array}$

'Will a 20-franc tip to the chauffeur be enough?'

(ibid.: 117, tr. 118)

One might imagine that the spoken version of this sentence would have a different intonation pattern than the corresponding statement, but to our knowledge Cárdenas (1923) says nothing about this.

Interlingua can indicate questions with the particle an, which "always occurs at the beginning of the sentence" (Gode \& Blair 1951: 41):

(60) An le precio de illo esse-va tres dollares? Q the price of that be-IMPF three dollars 'Was the price of that three dollars?' (ibid., OT)

Gode and Blair (ibid.) mention esque, which is "[a] collateral form of the interrogative particle" and say it "should not be used in

${ }^{27}$ We use $\mathrm{r}$ for a letter of Hom-Idyomo which we cannot reproduce here: it appears to be a script version of the letter $r$. 
the same text" as an. YNQs can also be indicated by subject-verb inversion; if there is an auxiliary verb it is the auxiliary which will be inverted with the subject:

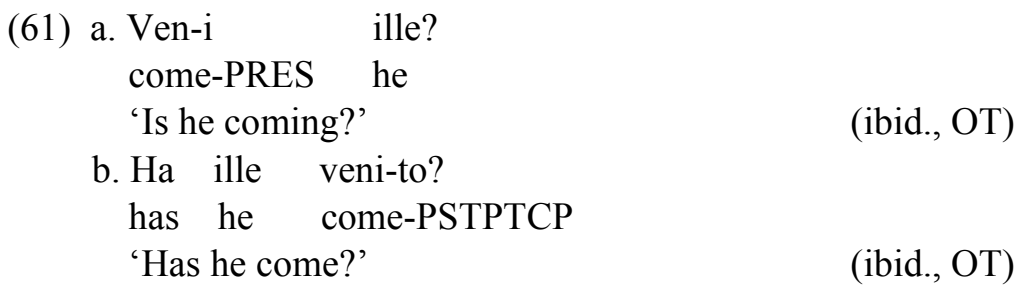

Interlingua also allows questions involving only a change in intonation (in the spoken language): Gode \& Blair (ibid.) state, "As in English every normal statement can be turned into a question by intonation and the use of a question mark". One of their examples of this is below:
(62) Le precio de ille cosalia esse-va the price of that stuff be-IMPF tres dollares? three dollars?
'The price of that stuff was three dollars?'

(One might again think that such questions seem like exclamations rather than neutral questions and wonder whether this is often or always the case with them in this and other ALs.)

Dutton Speedwords has an interrogative particle, $q$, and therefore, according to Dutton (1951: 18), a question mark is not necessary: "As the $Q$ plainly indicates that a question is being asked the note of interrogation (?) is eliminated in Speedwords sentences of this type." (WHQs do end with a question mark.) An example of a YNQ 
in this language is below ${ }^{28}$ :

(63) Q v sa qo g e?

Q you sa where they are

'Do you know where they are?'

(ibid.)

As in the languages discussed previously in this section, in Lingua Franca Nova YNQs can be created by inserting material at the beginning of a statement, although in this case we would not say that material consists of a particle, but rather two words: es ce, es being 'is', while ce means 'which', 'what', or 'that' (in the sense of a interrogative/relative pronoun and conjunction, but not of a demonstrative pronoun), e.g.:

\section{(64) Es ce tu parla Deutx? is that you speak German 'Do you speak German?' (Lingua Franca Nova Grammar, OT)}

(Compare the est-ce que of French.) YNQs can also end with si 'yes' or no 'no', e.g., Tu parla Italian, si? (ibid.). Presumably the choice of si or no depends on whether the speaker anticipates a confirmation or denial. Finally, in this language questions "may be indicated by rising intonation alone" (ibid.). In the Lingua Franca Nova Grammar it is specifically stated that a question mark must be

${ }^{28}$ Dutton (1951) contains several YNQs without $q$ but with inversion (and a question mark), e.g.:

(i) $\mathrm{E} \quad u m \quad \mathrm{k} \quad \mathrm{v} \quad \mathrm{Il} \quad \mathrm{des}$ e $\quad \mathrm{Ku}-\mathrm{d}$ ?

is anything that you particularly desire be include-PASS

'Is there anything that you particularly desire to be included?' (ibid.: 78, tr. 132)

We do not know whether there is some rule governing this, or whether there is free variation between YNQs with a particle and those with inversion (or whether these sentences are errors on Dutton's part). 
used after written questions: "In writing, questions always end with a final question mark (?). Tu parla Italian?"

\subsubsection{Word Order}

We have seen that in some ALs YNQs can be formed by means of either a particle or inversion. To our knowledge, the only way of forming this type of question in Eurolengo is through inversion. If there is an auxiliary, it will invert with the subject e.g., (65a); if there is only a main verb, it will invert (unlike in English), e.g., (65b):

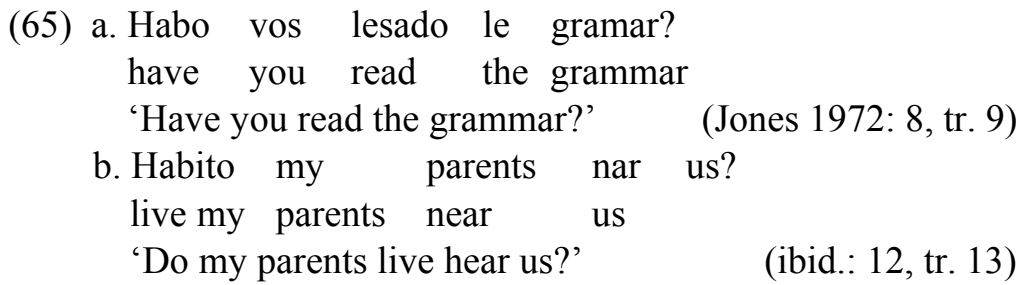

The Master Language was built from Latin, but none of the very few YNQs in Houghton (1907) (the only original source on the language to our knowledge) contains particles as Latin generally did; rather, subject-verb/auxiliary inversion occurs, and Houghton (1907: section 22) indicates that there is no do-support:

(66) Habitata ili homo isti domo?
inhabits that man this house

'Does that man live in this house?'

Another Latin-derived AL, SPL (or SIMP-LATINA), also has subject-verb inversion: Dominicus (1982: 13) states, "To form a question the Predicate is placed before the Subject: Edit canis panis? 'Is the dog eating bread? Does the dog eat bread?'" (Note 
that by "Predicate" he does not mean the entire predicate in the sense of the whole verb phrase.) However, unlike the Master Language, SPL allows for YNQ formation through particles, and indeed requires one of them when there is no overt subject: Dominicus (1982: 21) states, "In SPL, if it is impossible to form a question by placing the Predicate before the Subject, -ne must be added on the end of the first word of a sentence: Amasne me 'Do you love me?' (The accent shifts to the right)." In fact, even when there is an overt subject, -ne can, and perhaps sometimes must, appear: Dominicus (ibid.: 15) indicates that the SPL versions of the sentences Is the girl pretty? and Are the girls pretty? should begin with estne and suntne respectively, and in the answer key to this exercise, the translations indeed start this way, e.g., estne puella bella? is the translation of the former question. Note that when there is an overt subject, even when -ne is present, there is inversion. SPL marks non-present tenses and aspects (of almost all verbs) with a particle preceding the verb; in the examples which we know of containing both such a particle and -ne, the latter is attached to the former (rather than to the main verb):

(67) Fin-ne vide-t albae nubesae in celum? PERF-Q see-3SG white clouds in sky 'Did he see the white clouds in the sky?' (ibid.: 227, tr. 24)

In addition, SPL uses the particles nonne and num in the same way as Latin (and when they are present -ne is not attached to the verb or particle); the former with "a question expecting the answer YES" (ibid.: 67) and the latter in "a question expecting the answer NO" (ibid.), e.g.:

(68) a. Nonne sunt boni?

Q they.are good

'They are good, aren't they?' 
b. Num sunt boni?

Q they.are good

'They are not good, are they?'

(ibid.)

Esata has an interesting variation on inversion. ${ }^{29}$ Subject pronouns can form a single word with main verbs, along with auxiliary verbs, object pronouns, and other constituents. Whether this is able to happen depends on whether the items involved are words in the "Primary meanings list" (Pafu 2004: section 4), which consist of a single syllable. An example of this is yubiqi 'you are here' (ibid.: section 6). When inversion takes place in YNQs (and it is not clear to us whether it is required in (all of) them), if the subject and the verb/auxiliary are part of the same word in the corresponding statement, they will remain part of the same word, e.g., bihigo 'Is he going?' (ibid.: section 11). (Esata does not seem to use question marks.) Pafu (ibid.), perhaps speaking of questions in general, says that inversion "is generally used in case the subject is a pronoun".

\subsubsection{Intonation}

We have seen that some ALs allow YNQs to be formed by a change in intonation (from that of a statement). However, we know of no ALs for which this is clearly the only means of forming such questions, or at least the only procedure involved in their formation. Pan-kel might appear to be such a language, as Wald (1909: 7) states, "With questions one only raises the voice". However, he then has the following example, in which inversion has taken place (since usually subjects are in clause-initial position): libe $u$ 'Does he love?' His next example does not have inversion: $u$ kome 'Does he come?'

${ }^{29}$ Esata does have a particle, qe, "which at the start of any normal sentence converts it into a question, qe yu fami 'Are you hungry?" (Pafu 2004: section 11). 
Therefore inversion is not required in YNQs in this language.

\subsection{Wh-Questions}

WHQs will obviously involve a $w h$-word. However, they may or may not also involve a change in word order. For one thing, whmovement may or may not occur, and if it does occur one might ask whether it is optional or obligatory. There also may or may not be subject-auxiliary inversion (with insertion of an auxiliary if it is not present); again this could be optional or obligatory. (Apparent optionality could be the result of a language creator not following his own rules, i.e., he might state that inversion is required, but then not always have inversion in his own examples).

The following example indicates that SPL has both wh-movement and subject-verb inversion:

(69) Quid significant hoc vocabulum? what means this word

'What does this word mean?' (Dominicus 1982: 127)

When there is a tense/aspect particle, both it and the verb will invert with the subject:

(70) Fin leg-it puer bonus liber? PERF read boy good book 'Has the boy read a good book?' （ibid.: 227, tr. 24)

In Arulo inversion does not seem to occur in general:

(71) a. Qua urbon li kaptis? which city they took 'Which city did they take?' 
b. Quon el trovis?

what she find

'What did she find?'

(ibid.)

Interestingly, there is inversion when the verb is a copula:

(72) Qui esas li?

'Who are they

'Who are they?'

(Talmey 1925: 8)

Inversion can also occur in the presence of other verbs:

(73) En qua stacioni haltas la treno?

in which station stops the train

'In which station does the train stop?' (Talmey 1925: 10, OT)

(Notice that in this example the entire PP containing the wh-phrase has been moved to sentence initial position.) Assuming that such sentences are not errors on the part of the author, one might think that the difference between (71) and (73) has to do with whether the subject is a pronoun. (To our knowledge Talmey does not give an explicit statement on when there is inversion.) However, the following sentence is evidence against any such idea, since the subject is not a pronoun and there is not inversion:

(74) Kur la naturo exkavis bayi alonge la mar-bordo? why the nature excavated bays[?] along the sea-border 'Why did nature excavate bays along the seaside?' (ibid.: 19, OT)

Weilgart (1979: 49) explicitly states that there is "No inversion!" in questions in aUI, by which he seems to mean that there is no whmovement or subject-verb inversion (in any kind of question), since he says, "'What does he eat'=He eats what?" This can be seen in the 
following example:

$$
\begin{aligned}
& \text { (75) } \mathrm{Bu} \quad \varepsilon v \quad \text { he [?] } \\
& \text { you do what } \\
& \text { 'What do you do?' }
\end{aligned}
$$

However in the example below there is wh-movement, although not subject-verb inversion:

$$
\begin{aligned}
& \text { (76) Hud bu } \varepsilon v \text { fe? } \\
& \text { how you do this } \\
& \text { 'How do you do this?' }
\end{aligned}
$$

In fact, the majority of WHQs that we have seen in Weilgart (1979) involve wh-movement, and, to our knowledge (aside from questions containing copulas, to be discussed just below), the only wh-word which can be found in situ in WHQs is he 'what?' (and perhaps $h u$ 'who?', with respect to which one cannot tell whether wh-movement has applied).

As in Arulo, subject-verb inversion can be found when there is a copula; in the following questions $w h$-movement has also applied:

$$
\begin{gathered}
\text { (77) a. Ha cא bu? } \\
\text { where are you } \\
\text { 'Where are you?' }
\end{gathered}
$$

b. $\mathrm{H} \varepsilon \quad \mathrm{c} \Lambda \quad f \varepsilon$ ?

what is this

'What is this?'

(ibid.: 28)

However, not all WHQs containing copulas have such inversion (or wh-movement): 
(78) a. $\mathrm{Bu} \quad \mathrm{c} \Lambda$ ha you are where?

'Where are you?'

b. 'Fe c he?', au hIv.

this is what spaceman ask

“'What's that?', asked the Spacemen.' (ibid.: 173, tr. 174)

Note that (78a) is the same question as (77a), and in fact occurs on the same page of Weilgart (1979).

What is more, there are some WHQs in Weilgart (1979: 95) in which the $w h$-word is neither in situ nor in sentence-initial position, but in second position, after the subject and before the verb, e.g.:

(79) $\mathrm{Vu}$ ha tev-yec at bena?

he where come-CTF to land

'Where would he come to land?'

Meiko is also not supposed to have wh-movement or inversion in WHQs, e.g., To ete ko? 'You are eating what/What are you eating?' (Garet no date). Even in WHQs with a copula there does not seem to be wh-movement, given the following sentence: Meiko este ko? 'What is Meiko?' (ibid.).

SASXSEK does not have (required) $w h$-movement or inversion in WHQs, at least those in which the wh-phrase is a direct or indirect object:
(80) Vo don ho fu lo? you give what to him 'What did you give to him?'

(Nutter 2006: 38)

A wh-phrase which is a direct object can be placed in clauseinitial position "for better focus" (ibid.), in which case it will be preceded by the direct object marker $u$ (but there is still no 
inversion):

$\begin{array}{llllll}\text { (81) U } & \text { ho } & \text { vo don } & \text { fu } & \text { lo? } \\ \text { ACC } & \text { what } & \text { you } & \text { give } & \text { to } & \text { he }\end{array}$ 'What did you give to him'

Likewise, "Indirect objects may also be moved to give them focus" (ibid.). We do not know whether such elements can also undergo movement for focus in statements. The only two examples of WHQs that we know of in which the wh-phrase concerns time, and the two in which it concerns location or direction, do involve wh-movement, e.g.:

(82) Tu hi horas movo tem?
at which hour
'What time is it?'

We do not know what happens when the wh-word/phrase concerns manner.

In Esperanto WHQs "The wh-word normally stands at the beginning of the interrogative clause" (PMEG 22.1, OT). Presumably the same would be true of a wh-phrase consisting of more than just a $w h$-word. The PMEG (ibid.: 34.1.2) also says, "Before the wh-word can however stand a preposition" (and again, presumably this applies to a $w h$-phrase). ${ }^{30}$

\footnotetext{
${ }^{30}$ We have seen no indication as to whether preposition stranding is possible in Esperanto. If the definition of preposition in the PMEG (12.3) is to be taken strictly then it would not be: "Prepositions are little words, which one puts in front of phrases to show sentence roles." We do not know of any ALs in which preposition stranding is possible, with the exception of Essential World English; Hogben (1963: 114) implicitly allows it (and in fact seems to require it). One might expect the same to hold in other ALs which are simplifications of English. However, these are probably not significant facts, since English itself permits preposition stranding.
} 
(83) De kio tio ĉi ven-as, mia filino? from what this come-PRES my daughter 'From what does this come, my daughter?' (ibid., OT)

Further, "In principle also other words, which work together with the $w h$-word, can stand in front of it, but one generally hates to have something which is not a preposition before a wh-word" (ibid.). An example of this is the following:

(84) Kune kun kiu vi ven-is? together with whom you come-PST

'Together with whom did you come?'

(ibid., OT; after this example is the remark "One would normally abandon kune.")

WHQs in Interlingua are formed through $w h$-movement and subject-verb/auxiliary inversion:

(85) a. Quando arriva la traino? when arrives the train 'When does the train come in?' (Gode \& Blair 1951: 41) b. Que ha tu facito con tu moneta? what have you done with your money 'What have you done with your money?'

Wh-movement and subject-verb inversion take place in Eurolengo WHQs:

We also have no information on whether there are any ALs in which the Subjacency Principle does not hold (but see section 4), or on island constraints in ALs. This is not surprising given the fact that many works presenting ALs do not devote much space to syntax. 
(86) a. Ké fero Y?

what do I

'What am I doing?'

(Jones 1972: 10, tr. 11)

b. De kel via salo le tren for...?

from which way depart the train for

'From which platform does the train for ... leave?'

(Jones 1972: 78)

The same appears to hold for Hom-Idyomo:

(87) a. Kay kiel aplikay la governo la forco? and how applies the government the force 'And how does the government apply force?'31

(Cárdenas 1923: 38)

b. En kia domo habitay bi?

in which house live you

'In which house do you live?'

(ibid.: 39)

If there is an auxiliary verb, it will invert with the subject:

(88) Pro qwantas personos estay ji destinata?

for how.many people is it intended

'For how many persons do you wish it?'

(ibid.: 116, tr. 118)

There is one question in Cárdenas (1923) with its wh-word in second position, and the subject in first position (cf., the aUI example (79)):

31 Forco means "an effort having for its object the destruction of personal liberty" (ibid.: 31). 
(89) Wel, kay cias sufragos kio representay? well and those votes what represent

'Well, and what do those votes represent?'

(ibid.: 158)

Esata has wh-movement in WHQs and optional subjectverb/auxiliary inversion: Pafu (2004: section 11) states, "Following an interrogative, it is not necessary to invert the order of subject and verb. To retain similarity with English word order however, the inversion is acceptable." The example wehiviko/wevihiko "when will he come?' is then given. Notice that in this example we have inversion within a single word, which, as we saw above (section 3.2), can happen in YNQs in this language.

Wh-movement occurs in WHQs in Dutton Speedwords, while inversion seems to be optional: (90) a. ... qy s taf si axo?
why he delay his answer
'... why does he delay his answer?'

(Dutton 1915: 60, tr. 128)

b. Qy v y-ruf c kla-ca ap Why you PST-leave this class-room open debe dexi? yesterday evening

'Why did you leave this class-room open yesterday evening?'

(ibid., tr. 127)
c. Qo \& $\quad$ qe $\quad r \quad r \quad g \quad$ go ...?
where and when will they go
'Where and when will they go ...?'

(ibid.: 19)

We are not certain why this is, but we suspect that when there is an auxiliary verb (which happens less frequently than in English, since there is no $d o$-support), the subject will invert with it, but if there is only a main verb, there will be no inversion. 
It appears that Gilo has (something like) wh-movement in WHQs $^{32}$ :

(91) a. K re il rit-oz let?

Q reason he write-PST letter

'Why did he write a letter?'

b. $\mathrm{K}$ as $\mathrm{yu} \mathrm{x}$-ez?

$\mathrm{Q}$ place you live-PRES

'Where do you live?' (Giles 2006: section 12.2)

c. K ki bir yu f-ez?

Q kind beer you like-PRES

'What beer do you like?' [what kind of beer]

(ibid.: 12.4)

However, the wh-constituent can stay in situ: compare (91c) above with the following example.

$\begin{array}{lllll}\text { (92) } \mathrm{K} & \text { yu } & \text { f-ez } & \mathrm{k} & \text { bir? } \\ \mathrm{Q} & \text { you } & \text { like-PRES } & \mathrm{Q} & \text { beer }\end{array}$

'You like what beer?' [what kind of beer]

(ibid.)

The fact that what has been underlined here might make one think that this is an echo question, but we do not know whether this is the case. Notice that $k$ occurs twice, once in its usual position and once before bir (and that $k i$ has been left out; we do not know whether this is an error). What is more, the sentence-initial $k$ is not required in these cases, "[i]f the context is quite clear" (ibid.), e.g.:

\footnotetext{
${ }^{32}$ We say "something like" because, as can be seen, the equivalents of English whwords/phrases are made up of the interrogative particle $k$ and one or more other words, although they do not form a single word (at least orthographically). One could claim that only the other word(s) has (have) moved from its (their) in situ position, with the $k$ being attached to the beginning of the sentence, as with questions in general. However, the fact that when there is no wh-movement the in situ phrase contains $k$ (as we shall see below) argues against this.
} 


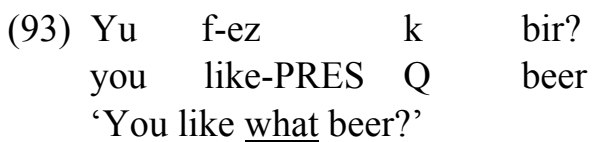

Note the absence of question marks in all the Gilo questions.

Like Gilo, Eurolang sometimes has a sentence-initial interrogative particle (as in YNQs) in WHQs, with wh-phrases remaining in situ $^{33}$ :

(94) a. Quiz tu lect qui?

Q you read what

'What are you reading?'

b. Quiz qui lect la journal?

Q who reads the newspaper

'Who is reading the newspaper?' (Hunt 1998: section 6)

Notice that the words which we have glossed as 'what' and 'who' are the same: in fact Hunt sees it as "a placeholder for what is being asked" (ibid.), meaning that word order is crucial in distinguishing subjects from objects. The interrogative particle is optional, "Where $q u i$ immediately follows quiz" (ibid.), i.e., where qui is a subject:

(95) Qui lect la journal?

who read the newspaper

'Who is reading the newspaper?'

(ibid.)

Wh-adverbs can either appear in situ or in sentence-initial position:

${ }^{33}$ Compare the remark of Butler (1965: 30) about Esperanto: "Do NOT use $\hat{c} u$ and a Ki-word together. $\hat{C} u$ kie li estas? (='Tell me whether where he is'!) is nonsense." A difference between Eurolang and Gilo is that in the latter language the unmarked situation seems to be wh-movement, while in the former the unmarked situation (and indeed the only possibility in some cases) is for the whphrase to remain in situ. 
(96) a. Quiz tu lect qua-placae?

Q you read where

'Where do you read?'

b. Qua-placae tu lect?

Where you read

(same meaning)

(ibid.)

The justification for this is that "In a declarative sentence of Eurolang, adverbs can go to the beginning" (ibid.); such examples then perhaps should be seen as involving adverb movement rather than $w h$-movement. In the examples which Hunt gives of whadverbs in sentence-initial position quiz is not present. In none of the Eurolang WHQs in Hunt (ibid.) is there subject-verb/auxiliary inversion.

In the Blue Language as well an interrogative particle occurs in WHQs $^{34}$ :
(97) a. Ka du ser-o Div? what $Q$ be-PRES God
'What is God?'
b. $\mathrm{Ka} \quad \mathrm{du} \quad \mathrm{u}$-spik-o? ${ }^{35}$
who Q PERF-speak-PRES

'Who has spoken?'

(Bollack 1900: 40)
c. Te du spik-o e-ka?
you Q speak-PRES GEN-what

'What are you speaking about?'

(Bollack 1899: 348)

\footnotetext{
${ }^{34}$ In spite of the fact that Bollack (ibid.: 349 ) states that "interrogation is always expressed by the staffword $d u$ placed before the verb" (or by tnu in negative questions), on the previous page is a question without it, Ka komo? 'Who comes?'. On the same page appears Ka man? 'which man?', but the absence of $d u$ here could perhaps be explained by the fact that this is not a complete sentence.

${ }^{35}$ As can be seen, the same word means 'who?' and 'what?'.
} 
$\begin{array}{clll}\text { d. Te } & \text { du } & \text { lago } & \text { kaч? } \\ \text { you } & \mathrm{Q} & \text { are.aged } & \text { how.much }\end{array}$

'How old are you?'

(ibid.: 349)

Note that in general the wh-word stays in situ, and Bollack (ibid.: 348) seems to specifically state that there is no wh-movement in his language, as its rigid word order does not permit it. However, in (97a) this fixed order does not hold, since the predicative phrase (i.e., the subject complement) is first and the subject last; perhaps questions such as (97a) are due to confusion of the subject and predicative phrase.

Apparently movement is optional in Lingua Franca Nova WHQs, at least for wh-adverbs: "Como ['how'], cuanto ['how much'], cuando ['when'], do ['where'], and per ce ['why'], when used as interrogatives, are essentially adverbs, and can come first in the sentence or right after the verb. 'How is he/she?' Como el es? El es como?" (Lingua Franca Nova Grammar). As in Eurolang, what is involved is arguably adverb movement rather than wh-movement.

In pan-kel wh-movement is not to take place in some WHQs: in general in this language there is freedom of word order; however, Wald (1909: 6) states, "If in sentences with $k i$ ['who'] or $k a$ ['what'] the subject is a noun [by which he may mean when the subject is headed by a noun], it [i.e., the subject] is at the front." This is because nouns (unlike some pronouns) do not bear overt case marking (and because interrogative pronouns also are not marked for case), and so word order is the way to distinguish subjects from objects. ${ }^{36}$ Thus, while 'Who defeated the Russians?' is translated as ki sigo rusi? (ibid.: 6), 'Whom did the Russians defeat?' is rusi sigo $k i$ ? (ibid.). Compare the following WHQ, in which the subject is a personal pronoun, and in which $k i$, indicating the direct object, does

${ }^{36}$ Subject initial order "is recommended" (ibid.: 9) generally in sentences in which nouns [noun phrases headed by nouns?] play both the subject and object roles. 
undergo wh-movement: ki oge o 'what do you see?' (ibid.). (We do not know whether wh-movement is required in such cases.) In this example subject-verb inversion has also applied (and again we do not know whether this is mandatory). Given the following examples, one might suspect that in WHQs in which confusion between subject and object will not occur (e.g., when the $w h$-phrase is not the object) $w h$-movement will be usual, if not required:
a. Ko suk-e o sem-eg? why sigh-PRES you sleep-PRESPTCP
'Why do you sigh when you sleep?'
b. Va t vo mu-o u? ? when and where be.born-PST he/she/it
'When and where was he/she/it born?'
(ibid.: 88, OT)
(ibid., OT)

\subsubsection{Multiple $W h$-Movement}

Since, as we have seen, some natural languages allow multiple $w h$-movement, one might wonder whether the same is true of any ALs. This is difficult to determine, since many or most AL designers give limited information on syntax. In fact, the only language that we can comment on in this regard is Esperanto, and even with respect to it we have not found any explicit statements either permitting or forbidding multiple wh-movement, only the following statement that it is not necessary: "If sometimes one has in the same question more than one interrogative $w h$-word, only one of them needs to stand clause-initially" (PMEG 22.1, OT). However, we have found some examples of multiple $w h$-fronting in Esperanto questions, two of which are below ${ }^{37}$ :

${ }^{37}$ In fact we have found an example of a question in which wh-movement has applied three times. Although it is an indirect question, which type of question we are not treating in this paper, it seems worthy of being cited here: 


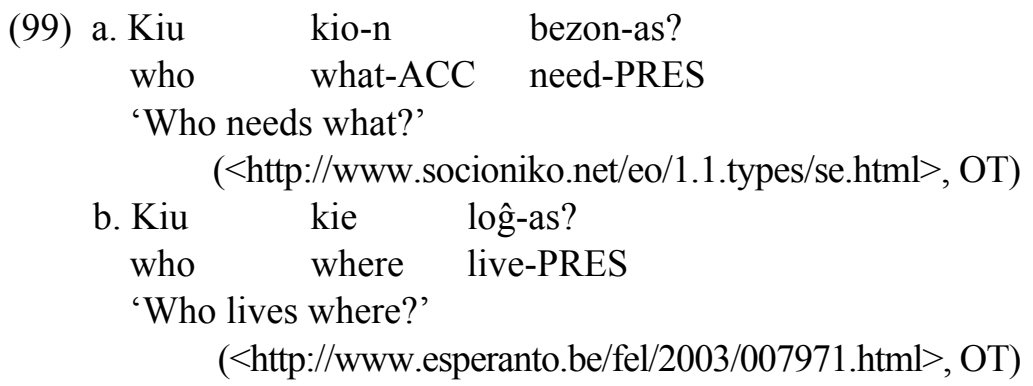

\subsection{Universals and ALs}

Having looked at question formation in ALs, we can now get an idea of to what extent they follow the universals brought up in section 2.6, i.e., (36) and (39), combined into (41). In fact, to our knowledge, there are no ALs that clearly violate them. ${ }^{38}$ Thus there

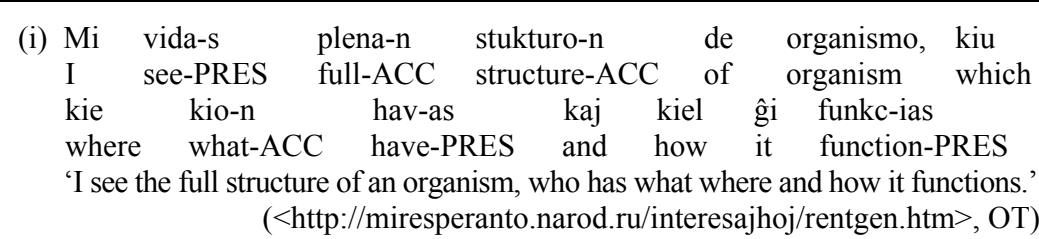

Interestingly, this is a translation from a Russian original (at the same URL) (and it may be significant that some of the examples of multiple wh-movement in Esperanto are from writers who at least know a Slavic language, if they are not native speakers of one), and in the original version $w h$-movement has only taken place twice in the relevant clause, with two of the $w h$-words joined by a conjunction: $y$ кого что $и$ где 'in whom what and where'.

${ }^{38}$ The situation is complicated by the optionality of inversion or wh-movement in some ALs; thus there are various ways of interpreting implicational universals of the type of (36) and (39). For example, does (36) mean if there has to be WHQ inversion there has to be $w h$-fronting, or that if there can be WHQ inversion, there has to be $w h$-fronting, or that if there can be WHQ inversion, the language has to at least allow for wh-fronting? This is why we say "clearly violate". We believe that a good way to see (36) is with respect to what can happen in a single question, that is, if a WHQ has inversion it must have $w h$-movement as well. Of course this manner of viewing a universal will not be applicable to (39). 
are ALs which have $w h$-fronting, and those which do not (at least not mandatorily), and there are ALs which have inversion, and those which do not, but we have found no WHQs in an AL in which inversion has occurred but $w h$-movement has not. We also are not aware of any ALs in which YNQ is required and in which WHQ inversion cannot occur. From one point of view these facts may not be surprising: since many ALs are based on natural languages, and since in any case, ALs are still human languages, we might not expect them to violate such universals. On the other hand, some ALs do have rather unusual properties, the most unusual one with respect to questions being, in our view, the apparent possibility in aUI and perhaps Hom-Idyomo for $w h$-phrases to move to second position in the sentence (as in (78)). Therefore, one might not be shocked to discover some ALs in which (41) or other universals are violated.

\section{Recommendations}

Second language acquisition literature (Eckman 1977, 1985; Hyltenstam 1984) presents evidence that the level of typological markedness is directly related to order and ease of acquisition of the grammatical system of the second language: less marked constructions are generally easier to acquire, and are (almost) always acquired before more marked constructions. Given that ALs are almost invariably acquired as a second language, learnability and processability issues should be taken into account when designing a new AL.

In light of this, we recommend that interrogative structures (and grammatical structures generally) should be marked uniquely, yet as minimally as practically possible. It would seem unnecessary to mark an interrogative construction with both a question marker (e.g., a QP) and a change in the order of constituents: one of them should be sufficient. For YNQs the simplest solution seems to be a QP with 
a fixed position in the sentence (preferably clause-initial position). One might argue that a "floating" (rather than fixed-position) QP would ensure a much greater flexibility in allowing questions to target specific sentence constituents (cf., the Bulgarian example (11)). While this is undeniably true, such flexibility will only come at the cost of greater learning and processing difficulties. In relation to this, it should be noted that much of what can be expressed with a "floating" QP (as in Bulgarian) could possibly also be expressed by topicalizing various sentence constituents (which incidentally occurs anyway in some of the Bulgarian examples provided in (11)). If topicalization already exists as part of this AL's grammar, then using topicalization in YNQs will come at no cost at all.

Although some natural languages and some ALs allow for marking YNQs by intonation alone, and although this might appear to be a simple and easy way of doing this, we would recommend that this possibility not be permitted: simply marking a question with a change in intonation may not clearly enough mark a YNQ as a question, while it if contains an interrogative particle, which only appears in questions, there will be no doubt about what kind of sentence it is. If, as we have recommended, this particle is required to be clause-initial, then a YNQ will immediately be recognized as such. If these recommendations are followed, the question of whether there should be subject-verb/auxiliary inversion is of less importance: in the absence of a particle a word-order change could be an important marker of a YNQ, but if a particle is obligatory, one might argue that it can be optional (or not permitted) without serious consequences. A decision on this latter matter might depend on how free word order in general is to be in the language.

In relation to the formation of WHQs, similar considerations apply: the optimal marking for such interrogative constructions should also be as simple and as unambiguous as possible. In the view taken here, $w h$-words alone are completely sufficient as a marker of WHQs. Although using additional indicators, such as wh- 
movement and/or subject-verb inversion, would make WHQs clearer and more explicit, they would also add to learnability and processability problems. We therefore believe that having whphrases in situ is a simple, yet completely adequate solution for WHQs in an AL.

One could argue that, since most natural languages (up to three quarters, according to Ultan 1978) do involve wh-fronting, this might be a preferable option for ALs. Further, according to some linguists (e.g., Huang 1982), all languages have wh-movement at an underlying level, and thus it could be regarded as a natural process of languages that at some level will not seem alien even to speakers of languages which at the surface do not appear to have it. A reply to this is that wh-movement does not bestow any obvious advantages on languages which use it, but significantly complicates the derivation of WHQs, especially in relation to constraints on syntactic movement, such as the Subjacency Principle.

If one did opt to require wh-movement, one might wonder about whether it is necessary to make any recommendations regarding the Subjacency Principle. It probably would not be, since most AL designers would not even contemplate allowing violations of it (largely because they are unaware of it), but we might mention the experiment which is reported on in Ellefson and Christiansen (2000), which involved teaching an artificial language which did not follow Subjacency. They found that "not only are constructions involving subjacency violations hard to follow in and by themselves, but their presence also makes the language as a whole harder to learn" (ibid.: 650). We therefore believe that it would be unwise to allow them in an $\mathrm{AL}$, although it may not be necessary to discuss them in a pedagogical work on one.

Another issue is whether WHQs should also involve the QP designated for YNQs in the same AL: this is an issue that deserves consideration since it could be argued that the use of QP in both YNQs and WHQs would add uniformity to the formation of 
interrogative constructions generally in this language and would therefore make the interrogative system easier to learn and use. On the other hand, this might be felt to be an alien feature by many AL learners, since it does not occur in some of the most widely spoken languages of the world. As with so many design questions facing those wanting to create an AL, the choices may not be easy or entirely clear-cut: a feature which might appear to give an advantage may also have disadvantages. The AL designer should consider carefully when formulating rules for question formation in his language, as these rules may have consequences for the learnability of the language.

\section{References}

Bolinger, D. 1968. Aspects of Language. New York: Harcourt, Brace and World.

Bollack, L. 1899. La langue bleue: Théorie complete. Paris: Editions of the Blue Language.

1900. Abridged Grammar of the Blue Language. Paris:

Editions of the Blue Language.

Butler, M. 1965. Step by Step in Esperanto (8th edition). Orelia: The Esperanto Publishing Company.

Cárdenas, C. 1923. Hom-Idyomo (2nd edition). Leipzig: Fischer \& Wittig.

Chapin, P. 1978. Easter Island: A Characteristic VSO Language. In W.

Lehmann (ed.), Syntactic Typology: Studies in the Phenomenology of Language, 139-168. Sussex: The Harvester Press.

Chomsky, N. 1986. Barriers. Cambridge, MA: MIT Press.

Cole, P. \& G. Hermon. 1998. The Typology of Wh-Movement: WhQuestions in Malay. Syntax 1.3, 221-258.

Dutton, R. 1951. Teach Yourself Dutton Speedwords. London: The English Universities Press.

Eckman, F. 1977. Markedness and the Contrastive Analysis Hypothesis. 
Language Learning 27, 315-330.

1985. Some Theoretical and Pedagogical Implications of the Markedness Differential Hypothesis. Studies in Second Language Acquisition 7, 289-307.

Eckman, F., E. Moravcsik, \& J. Wirth. 1989. Implicational Universals and Interrogative Structures in the Interlanguage of ESL Learners. Language Learning 39, 173-205.

Ellefson, M. \& M. Christiansen. 2000. Subjacency Constraints without Universal Grammar: Evidence from Artificial Language Learning and Connectionist Modeling. In L. Gleitman \& A. Joshi (eds.), The Proceedings of the 22nd Annual Conference of the Cognitive Science Society 645-650. Mahwah, NJ: Lawrence Erlbaum.

Garet, F. No Date. MEIKO. Available at $<\mathrm{http} / /$ garet.free.fr/florent/ meiko/ meiko en.htm>.

Giles, A. 2006 (C 1999, last revised 2006). Gilo Grammar. Available at URL <http://www.gilo.org/>.

Gode, A \& H. Blair. 1951. Interlingua: A Grammar of the International Language. New York: Storm Publishers.

Greenberg, J. 1963. Some Universals of Grammar, with Particular Reference to the Order of Meaningful Elements. In J. Greenberg (ed.), Universals of Language 73-113. Cambridge, MA: MIT Press.

Hawkins, J. 1999. Processing Complexity and Filler-gap Dependencies across Grammars. Language 75, 244-285.

Hogben, L. 1963. Essential World English. New York: W. W. Norton \& Co.

Houghton, S. 1907. The Master Language. Rome \& NY: Self-published. Online Version Available at URL <http://www.smart.net/ bartlett/ master.html>.

Huang, C. 1982. Logical Relations and the Theory of Grammar. Ph.D. Dissertation. Cambridge, MA: MIT Press.

Hunt, P. 1998. Eurolang Quick Reference. Available at URL $<$ http://web.archive.org/web/20011120073143/www.vision25.demon.c o.uk/el/qref.htm>. 
Hyltenstam, K. 1984. The Use of Typological Markedness Conditions as Predictors in Second Language Acquisition: The Case of Pronominal Copies in Relative Clauses. In R. Anderson (ed.), Second Languages 39-58. Rowley, MA: Newbury.

Jones, L. 1972. Eurolengo: The Language for Europe. Newcastle upon Tyne: Oriel Press.

Keenan, E. 1978. The Syntax of Subject-final Languages. In W. Lehmann (ed.), Syntactic Typology: Studies in the Phenomenology of Language 267-328. Sussex: The Harvester Press.

Kuno, S. 1978. Japanese: A Characteristic OV Language. In W. Lehmann (ed.), Syntactic Typology: Studies in the Phenomenology of Language 57-138. Sussex: The Harvester Press.

Lehmann, W. 1973. A Structural Principle of Language and its Implications. Language 49, 47-66.

Libert, A. \& C. Moskovsky. 2002. On the Form and Function of Reflexives in Artificial Languages. Journal of Universal Language 3, 97-132. 2003. A Survey of Relative Pronouns and their Uses in Natural and Artificial Languages. Journal of Universal Language 4.2, 61-116.

Lingua Franca Nova Grammar. No Date. Available at URL $<\mathrm{http}: / /$ linguafranca-nova.net/lfngrammar.html>.

Mallinson, G. \& B. Blake. 1981. Language Typology: Cross-Linguistic Studies in Syntax. Amsterdam: North Holland Publishing Company.

Moskovsky, C. \& A. Libert. 2004. Possibilities for Passives in Natural and Artificial Languages. Journal of Universal Language 5.2, 101-149.

Napoli, D. 1993. Syntax: Theory and Problems. Oxford: Oxford University Press.

Nutter, D. 2006. SASXSEK (Reference). Available at URL $<$ http://www. nutter.net/sasxsek/files/sasxsek_eng.pdf $>$.

Pafu. 2004. The New Personal International Language Esata (draft edition 0.2). Available at URL <http://www.beginnersgame.com/page 
25.pdf $>.{ }^{39}$

Ross, J. 1970. On Declarative Sentences. In R. Jacobs \& P. Rosenbaum (eds.), Readings in English Transformational Grammar 222-272. Washington: Georgetown University Press.

Sadock, J. \& A. Zwicky. 1985. Speech Act Distinctions in Syntax. In T. Shoppen (ed.), Language Typology and Syntactic Description 155-196. Cambridge: Cambridge University Press.

Talmey, M. 1925. Arulo. New York: Ilo Press.

Ultan, R. 1978. Some General Characteristics of Interrogative Systems. In J. Greenberg (ed.), Universals of Human Language Vol. 4: Syntax 211248. Stanford, CA: Stanford University Press.

Wald, M. 1909. Pan-kel, Leichtest Kurzsprache für den Weltverkehr $\left(4^{\text {th }}\right.$ edition). Gross-Beeren: Self-published.

Weilgart, J. 1979. aUI: The Language of Space (4th edition). Decorah, IA: Cosmic Communication Co.

Wennergren, B. 2005. Plena Manlibro de Esperanta Gramatiko (Version 14.0). Available at URL $<\mathrm{http} / / /$ bertilow.com /pmeg/>.

${ }^{39}$ This is the only name given for the author of this work. One might think that it is a pseudonym. 